\title{
A crise dos paradigmas e o marxismo entre os pesquisadores em trabalho e educação em universidades brasileiras*
}

\author{
Maria Onete Lopes Ferreira
}

Faculdades Integradas Maria Thereza

\section{Para início de conversa: expondo o cenário e o problema}

As transformações capitalistas, especialmente aquelas delineadas a partir da ultima década do século XX, visíveis, sobretudo, no âmbito da economia, resultaram numa contrapartida das áreas do pensamento. Desde então as reflexões teóricas vêm marcando a história com o despontar de novas formas de pensar. As análises econômicas, políticas, sociológicas, históricas, queiramos ou não, jogam-nos na cara estas mudanças. Inegavelmente, a atividade intelectual vive hoje uma reviravolta. A todo momento e em qualquer lugar nos deparamos com obras cujas abordagens fazem referências aos tempos atuais como um novo tempo, uma nova era. Uns afirmam que não há mais história, outros decretam o fim da geografia, e

* Texto apresentado no Grupo de Trabalho Trabalho e Educação, durante a $24^{a}$ Reunião Anual da ANPEd (Caxambu, MG, 7 a 11 de outubro de 2001). há os que batizam os novos tempos como tempos da pós-modernidade.

O certo é que a história mudou, e a mudança foi tão rápida e inesperada que até o novo século parece ter antecipado sua chegada. $\mathrm{O}$ fenômeno chamado globalização e o conjunto das mudanças no seio da indústria levam o mundo à convivência com um progresso tão contínuo que o "novo" já nasce velho. Essa forma de progresso, segundo alguns teóricos, remete ao passado a filosofia da história, as metanarrativas, as ideologias, a utopia e a própria modernidade.

Em meio a esse cenário, assiste-se também a uma mutação ideológica ${ }^{1}$ do perfil intelectual. Fazse presente na literatura e na academia uma revisão de posturas teóricas e o nascimento de novas teorias que desautorizam, sobretudo, aquele pensamento que

${ }^{1} \mathrm{O}$ uso do termo toma o sentido atribuído à categoria ideologia empregada no pensamento leninista, que, de acordo com Löwy (2000), diz respeito ao estilo do pensamento vinculado a uma posição social. 
se convencionou chamar de marxismo. A imagem do intelectual politicamente comprometido com os interesses das chamadas classes populares, tradicionalmente conhecidos como intelectuais marxistas (progressistas ou de esquerda), que nos anos de 1980 marcou minha passagem pela universidade, ficou no passado, na memória. O antigo compromisso político diluiu-se e as teorias são outras. A tradição marxista que fincou terreno na academia vai cedendo espaço para as análises fragmentadas, fortuitas, efêmeras, particularizadas. A escola não é mais a mesma, a universidade também é outra. Nasce desse cenário a inquietação aqui teorizada.

O eixo central do texto está, pois, relacionado ao que se pode chamar de crise nas ciências, especialmente naquelas ditas humanas; ou, o que é a mesma coisa, à crise de referenciais em que elas se encontram mergulhadas. Crise esta que espalhou por toda parte uma febre literária pela decretação de fins, e cuja cura é, ao mesmo tempo, receitada mediante argumentos em defesa do novo, via de regra revestido com os prefixos neo e pós. ${ }^{2}$

Colocando a questão de um ponto de vista amplo, a investigação aqui anunciada tratou de examinar a incidência (ou não) dessa crise entre uma parcela de pesquisadores no âmbito da relação Trabalho-Educação. Isto é, pretendi diagnosticar até que ponto as teorias da história resistiram entre esses pesquisadores em suas problemáticas investigadas. Noutras palavras: terão as investidas teóricas ditas pós-modernas encontrado eco entre os pesquisadores interessados especificamente em temas voltados para a relação entre o princípio da sociabilidade e a natureza da formação humana? Até que ponto as teorias historicistas, espe-

${ }^{2}$ Olhando-se com mais rigor para a essência dessa crise, não seria possível sugerir que a pressa em substituir conceitos, modo de pensar e, por que não dizer, a própria natureza da ciência, dentre outras coisas, está relacionada ao caráter ideológico do conhecimento? A tentativa de legitimação de interesses particulares não estaria colocando, para a ciência, a necessidade de negligenciar cada vez mais seus pressupostos historicamente construídos? cialmente o pensamento convencionalmente chamado marxista, ainda resiste entre esses intelectuais?

Nessa direção, dentro da crise um ponto em especial interessou-me mais de perto. Refiro-me à deserção da teoria marxista, pelos intelectuais, fato mais acentuado a partir do início da década de 1980. Daí decorre uma atenção especial à questão da destituição (ou não) de validade do legado marxiano - fato reivindicado não só por seus adversários, mas também por antigos adeptos - no interior desse "microuniverso" da pesquisa educacional. Com efeito, a questão central deste estudo consiste em averiguar, dentro da crise mais ampla da ciência contemporânea, a parte cabível ao marxismo. Assim, mais que uma hipótese, a natureza do estudo caracteriza uma indagação: está tal crise caracterizada em todos os espaços acadêmicos nos quais o materialismo histórico se constituía como tradição investigativa? Até que ponto os pesquisadores em educação se deixaram por ela influenciar? Qual é, portanto, o nível de compromisso desses intelectuais com velhas e novas teorias? Em que medida o abandono do marxismo se caracteriza no grupo investigado?

Óbvio que esta preocupação não é propriamente com o abandono em si. O fato preocupa porque, na prática, o mundo ainda materializa uma realidade constituída pela supremacia de uma classe minoritária e de seus interesses, em detrimento de condições dignas de vida para a maioria. Assim sendo, por serem as teses marxistas associadas à critica dessa condição de existência, elas continuam representando a melhor teoria já elaborada para pensar-se sobre esta realidade.

Nesta perspectiva, entendo que, no debate educacional, a deserção marxista em curso traduz-se numa preocupação com a própria escola como locus do saber, necessariamente partícipe de uma sociedade cada vez menos justa. Numa palavra, esse abandono representa uma lacuna importante na já fragilizada luta por justiça social. Fato que, a meu ver, pode ser compreendido como um enorme prejuízo para o embate social, uma vez que o avanço de uma prática pedagógica comprometida com os ideais transformadores ha- 
via acenado com uma possibilidade mais otimista de transformação da sociedade. Essas são razões pelas quais considerei pertinente conhecer com mais propriedade esse abandono no interior da pesquisa educacional.

Ao iniciar o levantamento do material (composto pelas teses), a expectativa que me acompanhava era a de encontrar um cenário pouco favorável à preservação do marxismo. Contudo, à medida que ia aprofundando-me na pesquisa, descobria que a convicção relativa ao marxismo ainda era uma tendência bastante forte entre os pesquisadores selecionados. As instituições componentes do universo investigado foram as seguintes: Pontifícia Universidade Católica de São Paulo (PUC); Universidade de São Paulo (USP); Universidade Estadual de Campinas (UNICAMP); Universidade Federal do Rio de Janeiro (UFRJ) e Universidade Federal do Rio Grande do Sul (UFRGS). A escolha das instituições observou a relevância destas nas discussões que resultaram na configuração do universo temático em estudo. ${ }^{3}$ As teses somaram ao todo 34, assim distribuídas: PUC/SP - 10 teses; UNICAMP - 11 teses; USP -6 teses; UFRJ -5 teses e UFRGS - 2 teses. Todas as teses foram defendidas entre os anos de 1994 e $1998 .^{4}$

${ }^{3}$ Com base neste critério também fizeram parte do universo investigado a Universidade Federal Fluminense (UFF), a Universidade Federal de São Carlos (UFSCar) e a Universidade Federal de Minas Gerais (UFMG). Contudo, estas não dispunham de teses compatíveis com a temática, no intervalo pesquisado. No caso da UFF, a não-existência de teses justifica-se pelo pouco tempo de criação do curso de doutorado (apenas três anos) à época da pesquisa de campo; na UFMG, porque a linha temática trabalho e Educação havia sido recém-implantada; e na UFSCar, por falta de demanda pela temática.

${ }^{4} \mathrm{O}$ critério definidor do período investigado foi notadamente de ordem histórica. Somente no início dos anos de 1990 é que a discussão sobre pós-modernidade e globalização alcança nível mais sistemático na produção intelectual nacional. Portanto, essa problemática, seguramente, só começaria a aparecer nas pesquisas das teses produzidas a partir daquela data. Nesse sentido, considerando que o tempo formalmente destinado ao doutoramento
Quanto ao substrato metodológico, tentei seguir as direções norteadoras de um estudo de cunho crítico. Nesse sentido, as cores do objeto aqui delineado devem aparecer isentas de qualquer pretensão de neutralidade. Elas traduzem a intervenção intencional com a qual direcionei meu olhar sobre as profundezas do objeto. Naturalmente esse olhar se orientou pelo rigor acadêmico, tanto no tocante à análise quanto às conclusões chegadas. Desse modo, os postulados e pressupostos característicos da dialética constituem o veio metodológico com base no qual a análise toma forma textual propriamente dita. Marx e Engels, Hobsbawm, Kuhn, Frigotto, Gentili, Konder, Andery, Löwy e Gramsci são exemplos de autores com os quais dialogo na compreensão da ciência e da própria realidade. Neles encontro, portanto, muitas das categorias e terminologias com as quais trabalho.

\section{As bases epistemológicas do problema}

As razões que motivaram a pesquisa têm sua origem numa inquietação pessoal quanto à tese de superação da modernidade no campo cientifico. Isto é, intriga-me sobremaneira a idéia de ruptura paradigmática do conhecimento. Ora, as rupturas metodológicas, ou até epistemológicas, no terreno da ciência sempre foram o objeto dos chamados filósofos desta área. ${ }^{5}$ Afinal, Galileu, Descartes, Kant, Newton, Hegel, Darwin, Marx, Comte, só para citar alguns, foram, em suas épocas, propositores de teorias que abalaram as estruturas paradigmáticas do pensamento tanto quanto influenciaram as gerações futuras. Em que pese as tensões e polêmicas que cada um deles levantou, continuaram todos inscritos na mesma es-

é quatro anos, 1994 pareceu-me o melhor momento para o início da pesquisa de campo, posto que, a partir desse ano, tornava-se possível contemplar os trabalhos iniciados após a entrada em cena do debate sobre globalização e pós-modernidade, que é, por assim dizer, o tema de fundo da pesquisa. O intervalo fecha-se em 1998 porque a coleta de campo iniciou-se em janeiro do ano seguinte.

5 Thomas Kuhn e Karl Popper são exemplos da afirmação. 
trutura paradigmática do conhecimento. Esse argumento, do meu ponto de vista, torna a pós-modernidade algo problemático. Parece também pertinente, contra a instituição de uma época pós-moderna, a indagação pela importância de uma ruptura na linha divisória da história ou da epistemologia.

Estaria o fenômeno dito pós-moderno por trás da debandada atualmente existente no campo do marxismo? A materialidade que lhe dá sustentação seria a mesma que tornou frágil, segundo alguns, os fundamentos do marxismo, sua "validade" por assim dizer?

De certo modo, desconfio que parte dos que se ancoram ou admitem a pós-modernidade serve-se desta muito mais como distintivo para suas teorias. Ou seja, não se preocupam com os fundamentos da proposição. Naturalmente, há os que a justificam por meio de argumentos metodologicamente postulados e racionalmente explicitados. Assim, antes de encarar o objeto de estudo propriamente dito, considerei necessário conhecer, mesmo que parcialmente, o sentido que estes últimos atribuem à chamada pós-modernidade. Para dar conta da tarefa, elegi como autores postulantes da pós-modernidade especialmente Lyotard e Vattimo, posto que, no campo da teoria, são eles que apresentam os postulados a que se filia a maioria dos que aceitam essa dita condição.

Obviamente, a pós-modernidade iria encontrar desdobramentos entre os teóricos cuja produção prioriza o terreno da educação. Mclaren, Giroux e Silva são bons exemplos. Como era esperado, as fundamentações de seus pensamentos estão amparadas nas mesmas teses das ciências sociais em geral. Por essa razão, tais autores não serão aqui analisados, uma vez que se estenderia demasiadamente a discussão, cuja finalidade não é exatamente a questão pós-moderna, mas sua influência, ou não, no âmbito da pesquisa relativa ao campo temático trabalho-educação.

Grosso modo, pode-se dizer que as tendências pósmodernas partem de dois tipos de leituras da realidade. Uma delas está representada pelas teses defendidas, dentre outros, por Lyotard (1989), cuja premissa de sustentação se baseia no argumento de não-necessidade de um fundamento seguro para o conhecimento nos dias de hoje. Assegura o autor que a atual forma de legitimação do saber abre mão do metadiscurso que fundava o conhecimento moderno. Essa ruptura ocorre graças ao fantástico desenvolvimento tecnológico em curso, o qual patrocina a saída da sociedade de sua condição industrial. Desse modo, a condição pós-industrial da sociedade, de seu modo produtivo, corresponde a uma outra cultura, a cultura pós-moderna.

Segundo Lyotard (1989), a credibilidade que o pensamento moderno depositava nas narrativas entra em declínio à medida que o progresso das técnicas e das tecnologias desloca o acento a elas inerentes para os meios de ação, em detrimento dos próprios fins. Historicamente, a mudança entra em gestação com o fim da Segunda Guerra Mundial ou, mais especificamente, com a saída do capitalismo da recessão dos anos de 1930, sob a proteção do keynesianismo, só vindo a ser consolidada mais tarde. Nesse sentido é que, para o autor, a pós-modernidade corresponde ao atual estado da cultura nas sociedades desenvolvidas. Noutras palavras: a condição pós-moderna diz respeito ao estado da cultura depois que esta é afetada pelas transformações que mudaram as regras do jogo no campo das ciências, da literatura e das artes no final do século XIX (idem, p. 11). O resultado de tais transformações é que atualmente a sociedade

\footnotetext{
[...] releva menos de uma antropologia newtoniana (como o estruturalismo ou a teoria dos sistemas) e mais de uma pragmática das partículas de linguagem: é a heterogeneidade dos elementos. Eles permitem a instituição apenas por setores: é o determinismo local. (idem, p. 12)
}

Ainda no tocante ao conhecimento, Lyotard lembra que, sob os efeitos da pós-modernidade, o saber sofre alterações nas suas duas principais funções: a de investigação e a de transmissão de conhecimentos. Vaticina o autor que o uso crescente das máquinas informacionais afetará a circulação do conhecimento, de forma tal que somente o saber traduzido em quantidade de informação, em linguagem de máquina será considerado. Nesse sentido, a hegemonia da informática imporá uma lógica que terá como con- 
seqüência a separação entre saber e sabedor. Pior ainda, o saber assumirá uma condição estritamente mercantil, será produzido para ser vendido, tendo sua valorização no consumo que, por sua vez, gerará nova produção e garantirá o valor de troca, naturalmente desmerecendo o seu valor de uso. Assim, a ciência pós-moderna alterará as regras do jogo da produção e da difusão de conhecimento, e isso terá implicações para a posição dos estados-nação de um modo geral.

A outra corrente proponente da pós-modernidade parte do postulado de que a noção de historicidade presente no pensamento moderno não tem mais sentido diante do progresso tecnológico. Um dos expoentes e formuladores dos argumentos dessa tendência é Vattimo (1996). De acordo com este autor, os fundamentos de uma ruptura pós-moderna remontam ao pensamento de Nietzsche e Heidegger: está em ambos o rigor filosófico para a dita condição pós-moderna. Afirma o autor que a problemática do "eterno retorno", em Nietzsche, e a ultrapassagem da metafísica, na filosofia de Heidegger, servem aos fundamentos pós-modernos. Segundo Vattimo, o pensamento de tais filósofos sustenta a tese pós-moderna porque foram eles que, pela primeira vez na história, criticaram a modernidade do século XIX. Contudo, no tempo em que escreveram ainda não era possível pensar em termos de ruptura crítica. Qualquer proposta de superação moderna, à época, implicaria continuar prisioneiro da lógica moderna.

No mundo atual, de acordo com Vattimo, estão colocadas as condições de fuga da lógica da modernidade. Não obstante, a idéia de ruptura crítica, de superação ou novidade na fenomenologia do espírito, em sua opinião, continuaria a inserir a pós-modernidade na linha da modernidade. Assim sendo, a pós-modernidade não deve ser reconhecida pelo apelo de mudança das coisas, mas pela característica destruidora da categoria do novo tomado como experiência de fim de história hoje vivenciada. Assegura Vattimo que há concretamente, na pós-modernidade, uma sugestão de fim da história. Fim de uma história com o sentido historicista. Fato relevante, porque torna cada vez mais problemática a historicidade como noção teórica. Pois
[...] na prática historiográfica e em sua autoconsciência metodológica, a idéia de uma história como processo unitário se dissolve, instalando-se na existência concreta de condições efetivas [...] que lhe conferem uma espécie de imobilidade realmente não histórica. (Vattimo, 1996, p. xi)

É, pois, no aspecto da não-historicidade que Vattimo encontra a identificação da pós-modernidade com Nietzsche e Heidegger (e todos os pensadores que se inscrevem na perspectiva da não-historicidade ou de "pós-historicidade"). ${ }^{6}$ De acordo com o autor, Heidegger era contrário à tese de historicidade no mundo técnico. A condição pós-histórica, tal qual Vattimo a compreende, é descrita como a condição em que o "progresso se torna rotina". O progresso tornado condição rotineira significa que

\footnotetext{
[...] as capacidades humanas de dispor tecnicamente da natureza se intensificaram, e continuam intensificando-se, a tal ponto que, enquanto novos resultados sempre se tornarão alcançáveis, a capacidade de planejamento os tornará cada vez menos "novos". (Idem, p. xii)
}

De acordo ainda com Vattimo, convive-se hoje com a "secularização" teórica da noção de progresso, sendo o pensamento contemporâneo marcado pela ausência de "uma filosofia da história". Isso implica que a imagem da história está vinculada à escolha do gênero literário. Em suma, a presença do caráter ideológico na escolha de quem faz sua narrativa é que atribui a ela um curso unitário.

Portanto, a associação do pensamento pós-moderno a Nietzsche e Heidegger está na "destruição da

${ }^{6}$ Segundo Vattimo, classificar a experiência atual em termos de pós-historicidade implica correr o risco de trilhar por um sociologismo simplificador cuja culpa é atribuída aos filósofos. Entretanto, se a base filosófica do argumento prima pela fidelidade à experiência, esse argumento deve considerar o "antes de tudo e geralmente", ou seja, basear-se em características da experiência que estão diante dos olhos de todos, tal qual fez a filosofia do passado, a fenomenologia husserliana, Heidegger em Sein und Zeit e Wittgenstein na análise dos jogos lingüísticos. 
ontologia" (realizada por ambos). Para Vattimo, a pósmodernidade oferece a possibilidade de pensar-se o homem numa concepção não-metafísica e não-platônica, isto é, elimina a necessidade da busca de um fundamento, porque pós-modernidade é também pósmetafísica. Isto é, a pós-modernidade deve estar ancorada numa concepção não-metafísica da verdade. No entanto, essa associação não implica a redução da verdade a emoções e a sentimentos "subjetivos", e sim no reconhecimento do vínculo da verdade com o monumento, com a "substancialidade" da transmissão histórica (Vattimo, 1996, p. xix).

No campo do marxismo, Frederic Jameson contempla a discussão sobre pós-modernidade, contudo sua análise distancia-se das demais. Para Jameson (1997), o chamado fenômeno pós-moderno caracteriza a lógica cultural do capitalismo tardio (o capitalismo em sua fase atual). Portanto, propõe que se tome o conceito de pós-modernidade como tentativa de apreender historicamente o presente, numa época cujo teor do pensamento tem a marca do esquecimento histórico. Nessa perspectiva, pode-se tomar o conceito numa dupla interpretação: 1) "exprime", correta ou distorcidamente, e de forma profunda, um irreprimível impulso histórico; ou 2) dependendo da nossa postura em relação a essa ambigüidade, ele "reprime" e desvia efetivamente tal impulso. No entanto, o autor admite ainda a hipótese de que a consciência pósmoderna seja apenas a teorização de sua própria possibilidade; nesse sentido, tão-somente mera enumeração de mudanças e modificações.

Ao pensar nesses termos, o autor está comparando o fenômeno pós-moderno ao modernismo, que demonstrava preocupações efetivas com o novo, tentando captar sua emergência. A diferença, segundo o autor, é que o pós-moderno

[...] busca rupturas, busca eventos em vez de novos mundos, busca o instante revelador depois do qual nada mais foi o mesmo, busca um “quando-tudo-mudou” [...], busca os deslocamentos e mudanças irrevogáveis na representação dos objetos e do modo como eles mudam. (Jameson, 1997, p. 13)
Assim, parece correto afirmar que Jameson pensa a pós-modernidade como sinônimo de pós-modernismo, que, por sua vez, nada mais é do que o momento seguinte ao modernismo. O modernismo resistiu enquanto subsistiam zonas residuais da "natureza" ou do "ser", nas quais a cultura podia fazer alguma coisa para reformar a referência ao mais velho, ao arcaico. Completado esse quadro, o papel do modernismo cumpriu-se, dando lugar ao pós-modernismo, que representa um mundo mais humanizado que o anterior; no entanto, um mundo no qual a "cultura" se torna uma autêntica "segunda natureza".

\section{Nas trilhas da pesquisa: uma apresentação das teses ${ }^{7}$}

É seguro que o papel da ciência ou do conhecimento - se se preferir, sua validade - só pode ser entendido quando tomado com base nas condições objetivas que levam à sua produção. Daí que não se possa tomar um objeto como referência para análise sem sobre ele concluir diante da realidade que o causa. Assim acontece porque a ciência, modernamente compreendida, significa uma tentativa de explicação da realidade, por conseguinte, uma produção metodologicamente formulada. Contudo, o método científico é parte da opção do cientista que investiga. A possibilidade de opção entre métodos, naturalmente, decorre das diferentes concepções de ciência vigentes num mesmo período histórico. Ora, numa sociedade permeada pelo conflito entre diferentes interesses, também as idéias são conflitantes, porque o pensamento humano reflete as mesmas diferenças que caracterizam o antagonismo entre os interesses. ${ }^{8}$ Por-

${ }^{7}$ Adianto desde já que, em razão das condições formais que norteiam o texto, as referências aos autores estudados terão apenas caráter exemplificador. Portanto, não serão feitas reflexões pormenorizadas ou citações mais extensas.

${ }^{8}$ Disso resulta que nem sempre a opção metodológica confere uma escolha consciente do indivíduo, posto que o homem parece tendencialmente, por comodidade ou talvez por ignorân- 
tanto, o método reflete as condições históricas concretas da sociedade que o produz.

As teses aqui constituídas em objeto de investigação, naturalmente, traduzem essa realidade ora afirmada. Elas protagonizam posturas metodológicas características da produção científica hodierna, por isso mesmo demarcam escolhas que, consciente ou inconscientemente, se refletem em ganhos para a classe social contemplada pela opção metodológica do pesquisador. Nesse universo investigado, predominou a concepção metodológica que atribui à ciência, mais do que a simples interpretação e atuação sobre o mundo: a possibilidade de revolucioná-lo, mediante uma convivência pautada numa ação consciente e crítica entre as relações travadas pelos homens e mulheres que o constituem. Nesse sentido, convergente com os interesses da classe constituída por trabalhadores, detentora dos mesmos interesses.

A título de informação geral, os textos diferenciam-se bastante quanto ao tema abordado. Uma tentativa de agrupá-los com base nas características mais comuns neles presentes resultou em dez subdivisões, quais sejam: a) qualificação/formação profissional e transformações produtivas; ${ }^{9}$ b) escola, sociedade e relações de poder; c) qualidade total e educação; d) pósmodernidade e educação; e) educação e economia; f) neoliberalismo e educação; g) educação e globalização; h) a categoria trabalho e sua relação com a formação humana; i) informática e educação; e, finalmente, j) a luta docente/sindical por autonomia. A origem dos objetos eleitos é igualmente bastante va-

cia, mais predisposto a aceitar o que é consensualmente imposto. Como o conflito entre interesses tem por característica a dominação de uma das partes, esta, por meio de um aparato ideologicamente constituído, envolve sutilmente a capacidade de apreensão do indivíduo em relação às divergências, tornando-o um ser passivo, com maior predisposição para a aceitação dos métodos dominantes sem ter que fazer escolhas.

${ }^{9}$ Embora o conceito de formação remeta a uma discussão científica, creio que não cabe aqui essa discussão, uma vez que pretendo apenas caracterizar a ênfase atribuída aos temas em torno dos quais os pesquisadores se debruçaram. riada, quer esteja ela na escola, na empresa ou nalgum lugar oculto da sociedade.

Dentre os temas classificados, o que atraiu maior interesse foi o que versa sobre a formação humana e/ ou qualificação profissional no contexto das atuais transformações produtivas, o qual concentra 12 trabalhos. Contudo, os objetos investigados não se repetem; cada pesquisador lançou seu olhar sobre um ponto diferente ou encarou o problema com base em um ângulo diverso. Considero significativo o fato de metade das teses voltadas para este tema tomar como problema a formação de mão-de-obra especializada. Aqui, a maioria dos pesquisadores direcionou o olhar investigativo para dentro das empresas. Encontramse dentre tais empresas: a montadora de automóveis da Fiat em Betim, MG; uma indústria (não identificada) de papel/celulose no interior paulista; uma cervejaria em São Paulo (também não identificada); a companhia telefônica de Santa Catarina e a IBM. Quanto às instituições educacionais, foram pesquisadas, dentre outras, o Serviço Nacional de Aprendizagem Industrial (SENAI) e uma escola conveniada de Petrópolis que prepara menores para a prestação de serviços menos qualificados nas empresas.

A categoria trabalho foi bastante recorrente entre os pesquisadores. Nada menos que 11 deles situaram-na diretamente no centro de suas investigações. Em apenas dois casos o conceito não é discutido nos parâmetros da concepção marxista. ${ }^{10}$ Nos demais, o conceito é sempre entendido como elemento integrador e transformador da relação homem-natureza, ligado à explicação da alienação, do valor, ou como conceito-chave para o entendimento da crise contemporânea do trabalho. Um bom exemplo é o texto de Trein (1994), o qual defende que uma compreensão

${ }^{10}$ Nestes casos, a alusão ao conceito consiste apenas na necessidade de relacioná-lo à discussão atual acerca da formação para as exigências do mercado. Barone (1997), por exemplo, recorre ao conceito chamando a atenção para o fato de que, para as empresas, a escolarização é percebida como mecanismo que deve estar na vida e no trabalho. 
precisa da crise vivenciada pelo projeto burguês, assim como a construção de um projeto socialista passa pelo estudo dos conceitos oriundos do marxismo. $\mathrm{Na}$ opinião da pesquisadora, o conceito trabalho não teve sua importância subtraída pela atual complexificação capitalista. Nas suas palavras:

[...] se o trabalho e sua divisão, ao longo do processo histórico de desenvolvimento do capitalismo, serviu para separar e ao mesmo tempo relacionar as atividades produtivas no campo e na cidade, da mesma forma que a indústria e o comércio, hoje, com a globalização do capitalismo, é ainda o trabalho que hierarquiza as relações internacionais entre os diferentes capitais e assim entre os estados nacionais.

(Trein, 1994, p. 43)

Algumas teses abordam questões de ordem estritamente subjetiva, a exemplo de uma análise do tratamento dispensado à individualidade humana, pela escola, ante o atual estado de desenvolvimento capitalista, tema da tese de Palangana (1997). Preocupa a autora, dentre outros, o fato de que as leis gerais que norteiam o desenvolvimento do capitalismo não ofereçam outra saída aos homens e mulheres senão a de dispor-se a seu jugo. Desse modo, para garantir a sobrevivência do sistema, torna-se necessária a supressão de qualquer traço de individualidade que não seja conveniente às relações sociais de produção capitalista. Este fato representa uma verdadeira degradação da condição humana, posto que, reduzido até o limite, resta ao indivíduo pouco mais que a capacidade de satisfazer ao capital. Afinal,

[...] quando a individualidade está reduzida a quase nada, quando o indivíduo é mero ponto de referência da força de trabalho em abstrato, o mercado, na disputa pelo comprador, apela para necessidades, gastos, interesses, para o "tipo de cada um". Apela, isto sim, para a velha, mas viva, necessidade de realização do indivíduo. Mesmo coisificado, ele não se esgota na racionalidade objetiva. (Palangana, 1997, p. 92)

Outro exemplo é do pesquisador Saretta (1998), que discutiu a relação entre o significado de lideran- ça no entendimento dos trabalhadores da escola básica e a sua acepção no contexto da ideologia da qualidade total. A julgar pelo autor, um dos dilemas dessa compreensão é que a retórica da qualidade apresenta uma definição de líder que contraria o conceito de liderança definido pelas pesquisas científicas. Nestas pesquisas, de acordo com Saretta, o líder é uma pessoa com tendências voltadas para as relações pessoais ou para as questões ligadas a exigências e tarefas, sendo raros os casos de indivíduos que combinem as duas tendências. No entanto, o líder definido pela retórica da qualidade é sempre alguém portador de ambas as capacidades, posto que o discurso que o define tem caráter meramente ideológico. Assim sendo,

\footnotetext{
[...] o líder em voga atualmente é aquele que refina o discur-

so reinante, como um modo de dizer o senso comum, como espelho do lugar comum, seja escolar ou societal global. Em outras palavras, embora muito se afirme que a inovação, a criatividade são exigências do líder contemporâneo, em realidade o indivíduo só consegue ocupar o lugar do líder institucional se reproduz com exatidão o jogo simulado e mistificador da qualidade total. (Saretta, 1998, p. 45)
}

Dentro da diversidade temática, foi também objeto de análise a política de informática na educação brasileira, caso de Moraes (1996). A pesquisadora lembra que, sob a lógica do capitalismo, o uso da informática na educação não contribui para a superação da alienação, e que os benefícios da tecnologia só serão reais se alinhados a um processo efetivo de luta pela superação da dominação humana.

Foram ainda temas motivadores à organização sindical e sua luta por autonomia nas universidades, contemplado por Dal Ri (1997), bem como a preocupação com o elo entre as políticas educacionais nos países periféricos - em sintonia com o projeto do Banco Mundial - e a ideologia da "globalização", tese do pesquisador Leher (1998). Lembra este autor que a globalização é também uma forma de continuidade da ideologia do desenvolvimento, na qual o combate à pobreza, anteriormente postulado pela ideologia desenvolvimentista, é substituído pelo "alívio da po- 
breza". Nesse sentido, o Banco Mundial utiliza-se da educação a fim de evitar a "tragédia da exclusão". Noutras palavras, a preocupação do Banco pode ser traduzida como a compreensão de que

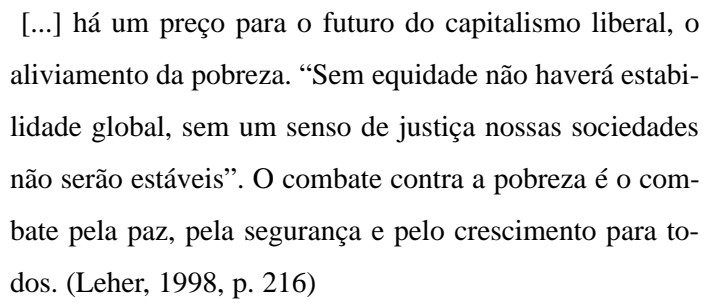

Esses são apenas exemplos dos temas e das preocupações norteadoras das pesquisas, cujos objetos são compatíveis com a linha temática Trabalho e Educação. Todos, exceto Saretta (1998), utilizam as categorias e conceitos do materialismo histórico e fazem referências a autores marxistas e ao próprio Marx em suas análises.

\section{Classificando as teses: o objeto e a natureza do estudo}

Para efeito dessa classificação, dividi as teses em dois grupos, um dos quais considerei de ordem empírica, comportando, portanto, as teses que investigaram a realidade de modo direto - isto é, aquelas em que, além dos documentos e leituras, seus autores utilizaram entrevistas e/ou questionários ou instrumentos como pesquisa-ação e pesquisa participante, para a montagem do texto. No entanto, trato como estudos de ordem teórica aqueles que tiveram como objeto de análise tão somente fontes escritas.

As teses nas quais o problemas investigativos tiveram fontes de ordem empírica podem ser divididas em dois eixos: a) textos amparados na crítica ao sistema e à escola e/ou ao ensino e b) estudos cujo teor é meramente descritivo, analítico, não-crítico. Com freqüência, as problemáticas estão relacionadas à qualificação profissional (cada vez mais ajustada às demandas do mercado). Como consequiência, a crítica mais recorrente nelas presente recai sobre a natureza ideológica dessa formação, bem como sobre os limi- tes refletidos na compreensão pelos empresários do que seja educação geral básica.

As teses direcionadas para o plano escolar versam sobre aspectos metodológicos, concepções de ensino, questões relativas à formação tanto do profissional necessário ao mercado quanto do trabalhador da área da educação, proposta curricular, qualidade total, a relação entre classe e gênero no magistério, dentre outras. Conforme frisado anteriormente, há pesquisadores que buscam nas fontes marxistas, e mesmo no próprio Marx, a referência para suas visões de mundo, afirmações e conclusões; outros, no entanto, negam categoricamente Marx, deixando clara a aceitação da tese de que o marxismo, como teoria científica, perdeu a capacidade de explicação do real; nessa direção, colocam-se como trabalhos afinados com as concepções que rompem com o princípio iluminista. Contudo, há casos em que a ausência do marxismo não se relaciona à negação da razão moderna, mas a opções de outras naturezas científicas.

De modo geral, os trabalhos que investigam o ambiente da empresa asseguram a compatibilidade entre estas e as definições de empresa reestruturada, logo, inseridas no contexto das novas exigências de mão-de-obra. Os pesquisadores mencionam a existência de cursos qualificacionais oferecidos pelas próprias empresas, ou por elas financiados para seus funcionários, havendo ainda casos em que a empresa possui faculdades (dentre estes, coloca-se a cervejaria). No entanto, de acordo com os textos, quase sempre a qualificação oferecida pela empresa restringese às exigências das funções de cada setor interno.

\section{Sobre os estudos oriundos de investigações empíricas}

Dezoito das teses analisadas tiveram objetos de natureza empírica. Nesse universo, os temas abordados diversificam-se quanto à perspectiva de análise $\mathrm{e}$ quanto ao que concerne à especificidade da problemática; entretanto, possuem em comum, direta ou indiretamente, a fonte ou origem de que emana o objeto, bem como o problema a este relacionado. Com 
efeito, dez pesquisadores elegeram como tema alvo de suas investigações questões subjacentes ao plano escolar e/ou ao ensino; os demais fixaram a atenção em temas educativos ligados ao terreno empresarial. Destacam-se as análises voltadas para a relação entre as necessidades constituídas pelo mercado e as conseqüentes implicações para a formação humana, e ainda as reflexões que versam sobre a importância do trabalho na prática educativa.

Quanto ao referencial teórico metodológico, aproximadamente dois terços (11) do total das teses ditas empíricas estão amparadas em análises identificadas com as categorias metodológicas inerentes ao materialismo histórico-dialético. Dentre esta, seis apontaram o holofote para temas vinculados especificamente ao ensino ou à escola. Nelas, além da questão do "trabalho como princípio educativo", emergem preocupações acerca das implicações decorrentes da implementação da ideologia da qualidade total na educação, assim como dos riscos do uso da informática no ensino, dentre outros.

Cabe como exemplo a tese de Bezerra (1997), cujo objeto consiste na definição de uma proposta curricular para a escola pública amparada precisamente no princípio educativo do trabalho. De acordo com a pesquisadora, essa empreitada tomou como base sua experiência frente à Secretaria Municipal de Educação em Aracaju. Ela assegura que a concepção de trabalho que orientou essa proposta tinha como horizonte o fato de ser o trabalho, como definiu Marx, uma categoria ontológica tipicamente humana.

Outro bom exemplo é o texto de Gonçalves (1995), que, tomando como tema o princípio educativo do trabalho, voltou-se para a questão dos fundamentos metodológicos do conhecimento, especialmente preocupada com o problema da interdisciplinaridade. Em sua opinião, o fim da marginalização, da subserviência passiva, e mesmo da alienação do trabalhador, remete a uma concepção de ensino cuja base crítica, no que diz respeito ao método, terá que ser buscada em Marx e em Gramsci. Adianta Gonçalves que um trabalho pedagógico à luz da crítica destes autores será capaz de garantir
[...] a unidade indissociável entre atividade teleológica e a atividade cognoscitiva, numa dimensão que signifique não apenas a interação de saberes, mas também a superação de toda forma de reducionismo e de a-historicismo. (1995, p. 153)

No tocante às teses voltadas para o ambiente empresarial, é válido afirmar que elas tiveram como eixo reflexivo análises críticas sobre os vínculos entre a reestruturação capitalista e a formação educacional dos indivíduos advogada pela visão dominante. No entanto, nem todos elegeram as categorias marxistas, caso, por exemplo, de Pereira (1994), cuja interlocução principal priorizou as categorias habermasianas. Dentre outras coisas, a autora considera que a contribuição de Habermas às análises do mundo do trabalho nas condições atuais é possível porque o autor propõe duas racionalidades: uma instrumental e outra crítica. Desse modo, pode-se pensar a empresa como representada por uma dualidade organizacional decorrente da racionalidade crítica e instrumental. Portanto, o pensamento de Habermas

\section{[...] fornece elementos para uma crítica do presente baseada na justificativa de que existem, pelas pressões crescentes do "dinheiro e do poder", por exigências do capitalismo, uma racionalidade técnica e uma consciência tecnocrática que se generalizam, mas que ao seu lado encontra-se ainda uma outra racionalidade, a razão comunicativa. (Pereira, 1994, p. 77)}

Pereira afirma ainda a concordância com as críticas que postulam a incapacidade das categorias do marxismo como categorias dotadas de poder de análise na atual realidade. Mas, em sua opinião, o limite está no pensamento marxiano, e não na ciência moderna.

Além de Pereira, outros seis autores de teses empíricas referenciaram-se em análises fora do campo marxista. Em três delas, a abordagem do problema tem base na escola; Pereira e outros três apresentam a empresa como fonte geradora das preocupações temáticas, as quais igualmente versam sobre mercado de trabalho e formação humana. No que pese o afastamento do marxismo, a orientação metodológi- 
ca desse bloco se mantém nos marcos da modernidade. Os textos apresentam características como análise fenomenológica do objeto, caráter objetivista da ciência, dentre outros.

\section{Breve exame das teses de natureza teórica}

A maioria dos pesquisadores que centralizou suas análises em fontes teóricas tomou como referência o marxismo. Quase todas as temáticas são singulares, sendo originais quanto à proposição das situaçõesproblema relativas à complexidade da presente realidade. Com efeito, elas partem de questões referentes à política de ciência e tecnologia, à formação do profissional no contexto de reestruturação produtiva; transitam pela complexa relação entre educação e cidadania; revisitam o dilema das possibilidades de autonomia da escola; passam pelas trilhas pós-modernas e pós-industrial; visitam a globalização, o discurso da qualidade, o da privatização; excursionam pela questão do trabalho como princípio educativo; e, finalmente, aterrissam no interior da Confederação Nacional da Indústria.

Como exemplo dessa pluralidade temática, podese destacar o texto de Peixoto (1997), cujo problema central diz respeito ao tratamento dispensado à democracia nas concepções pós-modernas. Um dos limites encontrados pela pesquisadora em relação à pósmodernidade na prática educacional seria que

\footnotetext{
[...] a junção da educação com concepções pós-modernas, que têm como fundamento a anti-história, a negação da possibilidade de transformação, o etéreo e o volátil é, além de um "modismo" sem sentido, um risco de se confundir educação com práticas adestradoras, que, em nome de um discurso "avançado", nada mais fazem do que perpetuar as relações sociais e o caráter excludente de nossa sociedade atual. (Peixoto, 1997, p. 281)
}

Fiod (1994) investiga o processo de desorganização sofrido pela escola como decorrência da desorganização da sociedade. A autora, por meio de uma análise criteriosa através da história, afirma que a escola, por ser parte da sociedade, tende a desorganizar-se em conseqüência da desorganização da própria sociedade.

É importante frisar que os vínculos mais claros entre as problemáticas pesquisadas e o tema "trabalho e educação" colocam-se a partir da relação que os pesquisadores estabelecem, em suas análises, entre o objeto pesquisado, o desenvolvimento produtivo e a educação. Nesse sentido, nem sempre é possível uma associação direta entre o título do trabalho e as cercanias do objeto aqui explicitado. Lopes (1997), por exemplo, dedica-se a um estudo acerca da resistência protagonizada pela universidade brasileira, por intermédio dos docentes, diante da política de ciência e tecnologia implementada pelo regime militar, chamando a atenção para a relação entre ciência e desenvolvimento produtivo como lógica da pesquisa universitária.

É possível perceber que, geralmente, a opção critico-metodológica dos pesquisadores, inclusive os citados, está amparada nas categorias do marxismo, o que demonstra a opção metodológica dos autores. Mas a dedução não é decorrente somente da crítica ou do uso de categorias pertencentes ao marxismo, é também uma condição reivindicada a priori pelos pesquisadores. Diante dessa opção, Marx e os autores marxistas não poderiam deixar de aparecer nos textos. Aliás, os pesquisadores deixam claro que a obra de Marx é dotada de importância fundamental para o entendimento do capitalismo, ou mesmo das questões relacionadas à escola, que sob a ótica da concepção dominante é perpassada pela falsa crença de que resolver os problemas da educação equivale a resolver os problemas da sociedade, o que implica, uma vez mais, colocar a escola à mercê de discursos que confundem a questão social com a cultural.

Há pesquisadores que trazem para o debate o mais sólido dos pilares que diferenciam a concepção de ciência em Marx daquela da ciência burguesa, qual seja, o da luta de classes. A título de exemplo, esta categoria é tomada de modo central na análise de Chinali (1998), cuja meta consistiu numa investiga- 
ção acerca dos impactos mútuos entre a educação e a estrutura de poder social, suscitados pela reorganização do capitalismo no atual contexto. A natureza do estudo baseia-se na tese de que "a atividade do educador adquire sentido e intencionalidade em função do desenho das relações econômicas e sua contextualização política" (Chinali, 1998, p. 3). A preocupação do pesquisador decorre do falseamento ideológico atribuído ao conceito de luta de classes no processo de globalização. Em sua opinião, o caminho que conduz à globalização econômica mundo afora gera uma situação ideológica na qual a burguesia nega o clima de guerra instalado pelo caráter predatório das relações sociais, o que, conseqüentemente, implica a autonegação de sua condição de classe.

\section{Considerações finais}

Conforme exposto, há boas razões para afirmar que, no tocante aos pesquisadores em "trabalho e educação", o marxismo ainda se constitui como paradigma possível e necessário para a compreensão dos problemas do nosso tempo. Dos 34 pesquisadores estudados, somente 10 produziram teses que não se alinham com o materialismo histórico. ${ }^{11}$ Mesmo entre estes, há teses em que os autores marxistas aparecem no texto; nestes casos, o que os afasta do materialismo histórico não é a negação da razão moderna ou dos pressupostos do Iluminismo, mas a opção metodológica na qual o texto se ampara. Seguramente, cabe afirmar que tais pesquisadores não se encantaram com o "charme" das teorias pós-modernas. Ao menos aquela parcela que defendeu suas teses entre os anos 1994 e 1998, período contemplado pela pesquisa.

Ao transitar pelas páginas do material colhido e analisado, fui constatando que a opção pelo pensamento marxista era muito mais forte do que eu própria imaginava. Sem recorrer ao otimismo, o estudo

${ }^{11}$ Em apenas três casos os pesquisadores optaram pela negação explícita de Marx, defendendo a pós-modernidade como condição atual. permite concluir em favor da superioridade do marxismo no terreno pisado pelos pesquisadores, cujas teses, produzidas nos programas de pós-graduação em educação, atinam com a área temática Trabalho e Educação. Apontando os números: $70 \%$ das teses investigadas demonstram a opção pelo marxismo. Nesse sentido, os novos pesquisadores contrariam aquilo que Kuhn (1975) aponta como tendência normal dos praticantes de uma ciência em tempos de crise. De acordo com Kuhn, são os novos pesquisadores que em primeiro lugar começam a abandonar a teoria, sendo que os mais antigos se mostram mais perseverantes. A julgar pelas publicações mais recentes, fica evidente que, dentre os autores brasileiros que colaboram na criação da área temática em tela, alguns já reviram suas antigas convicções. ${ }^{12}$

É certo que esses autores representam uma parcela pequena do universo dos pesquisadores de pósgraduação em educação no país, e menor ainda se tomada toda a pesquisa desenvolvida por profissionais do ensino. Contudo, é significativo o fato de pertencerem àquele segmento cuja origem está associada às discussões mais características da introdução do pensamento marxista na educação brasileira, na década de 1980. Talvez não seja prudente afirmar que o fato indique solidez do marxismo no campo educacional, mas é, seguramente, uma evidência de que este referencial não desapareceu. Que ainda está no ar a promessa de construção de uma escola pública de qualidade, comprometida com um saber que rompa com a opacidade do conhecimento nos moldes das teorias identificadas com a ideologia burguesa e suas teses pós-modernas.

${ }^{12}$ A afirmação toma por base, sobretudo, Tomaz Tadeu da Silva e Paolo Nosella. O próprio Silva (1993) explica sua opção pela pós-modernidade alegando que a postura anterior fora fruto de uma analise ingênua e apressada. Já Nosella, além de vir optando por objetos fora da temática, tem ainda demonstrado um abandono sistemático das categorias próprias do marxismo que faziam parte de seu repertório inicial, o que é visível, por exemplo em seu texto Qual compromisso político? (1998). 
Certamente a opção pelo marxismo não significa a negação dos problemas enfrentados pela teoria. Há pesquisadores que, além de mencionar o fato, criticam certas tendências do legado marxista. No entanto, continuam a ver nas idéias herdadas de Marx a fonte mais viável para continuar-se pensando uma saída alternativa que dê continuidade tanto ao sonho como à luta pela construção de uma sociedade socialista. Sobreira (1995), por exemplo, ao pensar uma teoria dialética da formação do professor, postula como um dos pilares fundamentais de tal teoria o conceito de prática social. Contudo, defende em primeiro lugar um repensar deste conceito. $\mathrm{O}$ repensar de que fala o pesquisador consiste numa apreensão dialética da relação sujeito-objeto, que, em sua opinião, na maioria das vezes é tomada como momentos determinantes e unilaterais. Acredita ainda que as circunstâncias atuais estão exigindo um avanço nas discussões marxistas, o que pode ser feito com base em categorias específicas ou num esforço de reconstrução da teoria como um todo. Nesse sentido, o autor argumenta que o entendimento do conceito da categoria "trabalho" deve apreendê-lo como elemento autoformador do gênero e do sujeito humano.

Portanto, no que pese a convivência e, talvez, a predominância da moda pós-moderna, o marxismo resiste, não para dar razão a Marx, mas para afirmar que a luta pelo socialismo jamais saiu de pauta. Que mesmo quando esta luta perde força nos percalços da estrada, há disposição para persistir. Acima de tudo, porque um sonho sonhado pela maioria até pode se arrefecer diante de obstáculos, como a pressão ideológica exercida pela mídia, mas as mentiras, ainda que bem produzidas, não são eternas; logo, jamais embalarão para sempre as noites maldormidas de homens e mulheres. Assim sendo, a força do sonho há de restabelecer a luta.

Diante da encruzilhada projetada pelas discussões, ditas científicas, da atualidade, não há como não lembrar de Kuhn (1975), quando afirma que os intelectuais desprezam a história, visto que as teorias apresentam, via de regra, um caráter aistórico. Mais que isso, parece necessário ter em vista que a ciência não muda pela imposição da vontade, mas quando a teoria que a fundamenta se revela incapaz de responder aos anseios e problemas trazidos pelo progresso da história. Progresso que expressa a capacidade, própria dos seres humanos, de transformar a natureza a fim de adaptá-la às suas necessidades, que também evoluem dialeticamente nesse processo.

Não estava a razão com Hobsbawm (1995), ao alertar sabiamente que a tarefa central posta para os intelectuais do novo milênio não deveria ser a de regozijo sobre o cadáver do comunismo soviético, mas a de reflexão sobre os efeitos inatos do capitalismo? Se é verdade, então, como ele mesmo propõe, a grande tarefa hoje posta está em pensar sobre as mudanças que renovam este sistema, sem contudo perder de vista sua velha lógica, dado que tais mudanças não podem ser tratadas à parte, porque são tão inerentes a esse sistema quanto as batidas do coração pertencem ao organismo que as apresenta.

Parece, pois, que os pesquisadores investigados neste estudo souberam entender essa lição. É o que indica Chinali (1998), ao assinalar que cabe aos educadores a tarefa de interpretar de forma adequada as novas condições criadas pelo desenvolvimento das forças produtivas e pelas correspondentes condições histórico-políticas, para melhor subsidiar suas práticas político-pedagógicas. Ademais, segundo lembra ainda esse pesquisador, a educação humana, como qualquer outro item da cultura, insere-se nas possibilidades de elaboração de respostas utilizadas, em cada situação específica, pela classe dominante (Chinali, 1998, p. 170).

Seguramente, as lições de Marx e as daqueles que depois dele contribuíram para uma leitura crítica do capitalismo serão bem-vindas para o desvelamento desse cenário cada vez mais comprometido com os interesses burgueses - portanto, coloridos de ideologia. Como já dizia Hobsbawm (1983, p. 63), enquanto o capitalismo for suscetível a críticas, o marxismo poderá ser transformado, mas é impossível que desapareça. Afinal,

\section{[...] as modas intelectuais mudam e muda o ponto de equi-}

líbrio no debate entre os estudiosos. Todavia, é extrema- 
mente improvável que o posto obtido por Marx no universo intelectual de nosso século, o estímulo encontrado por muitos intelectuais no marxismo e as discussões desenvolvidas em torno dele não prossigam no futuro, a menos que sejam destruídos todos os livros ou a civilização humana seja aniquilada em sua forma atual. (Hobsbawm, 1983, p. 63-64)

Ademais, as prerrogativas de Hobsbawm parecem concorrer para a tese da filosofia da ciência que reivindica a teoria historiográfica da história legitimidade para o progresso cientifico. Sendo assim, todo progresso científico é conseqüência de um processo revolucionário inerente à própria ciência em situações de crises.

MARIA ONETE LOPES FERREIRA, doutora em educação pela UFScar, é atualmente professora adjunta nas Faculdades Integradas Maria Thereza, em Niterói, RJ. Publicou: Neoliberalismo, pós-modernidade e educação: algumas implicações ( $E d u$ cação em Debate, 1998); A crise dos referenciais e os pesquisadores em trabalho e educação: o lugar do marxismo entre os educadores (ANPEd, 24 a Reunião Anual, CD-ROM). E-mail: onetelopes@hotmail.com; netelopes@stamedia.com

\section{Referências bibliográficas}

ANDERY, Maria A. et al., (1988). Para compreender a ciência: uma perspectiva histórica. São Paulo: EDUC; Rio de Janeiro: Espaço e Tempo.

BARONE, Rosa E M., (1997). O espaço do trabalho e da educação na construção civil. Tese de doutorado. Faculdade de Educação da Pontifícia Universidade Católica de São Paulo.

BEZERRA, Ada A. C., (1997). Gestão democrática da construção de uma proposta curricular no ensino público. Tese de doutorado. Faculdade de Educação da Universidade de São Paulo.

CHINALI, Luiz Alfredo, (1998). Fênix e a globalização ou Malthus revisitado. Tese de doutorado. Faculdade de Educação da Universidade Estadual de Campinas.

DAL RI, Neusa M., (1997). Sindicato, autonomia e gestão democrática na universidade. Tese de doutorado. Faculdade de Educação da Universidade de São Paulo.
FIOD, Edna G. M., (1994). Homens sem paz: escola, trabalho e colonização. Tese de doutorado. Faculdade de Educação da Pontifícia Universidade Católica de São Paulo.

FRIGOTTO, Gaudêncio, (org.) (1998). Educação e crise do trabalho: perspectiva de final de século. Petrópolis: Vozes.

(2000). A nova e velha face da crise do capital e o labirinto dos referenciais teóricos. Texto apresentado na $23^{\mathrm{a}}$ Reunião Anual da ANPEd. Caxambu.

(1995). Trabalho, conhecimento, consciência e a educação do trabalhador: impasses teóricos e práticos. In: GOMES, C. Minayo. Trabalho e conhecimento. São Paulo: Cortez. GENTILI, Pablo, (1997). Educar para o desemprego: a desintegração da promessa integradora. Palestra proferida na $20^{\mathrm{a}}$ Reunião Anual da ANPEd. Caxambu.

GIROUX, A. Henry, (1993). O pós-modernismo e o discurso da crítica educacional. In: SILVA, Tomaz Tadeu da. Teoria educacional crítica em tempos pós-modernos. Porto Alegre: Artes Médicas.

GONÇALVES, Maria D. de S., (1995). Autonomia da escola e neoliberalismo: Estado e escola pública. Tese de doutorado. Pontifícia Universidade Católica de São Paulo, Programa de Pós-Graduação em Educação.

GRAMSCI, Antonio; (1999). Cadernos do cárcere. v. 1. Rio de Janeiro: Civilização Brasileira. Tradução de Carlos Nelson Coutinho.

HOBSBAWM, Eric, (1995). A era dos extremos: o breve século XX - 1914-1991. São Paulo: Companhia das Letras. Tradução de Marcos Santa Rita.

, (1987). História do marxismo. O marxismo na época da terceira internacional: o novo capitalismo, o imperialismo, o terceiro mundo. Rio de Janeiro: Paz e Terra. Tradução de Carlos Nelson Coutinho, Luiz Sergio N. Henrique e Amélia Rosa Coutinho.

HOBSBAWM, Eric, (org.) (1983). História do marxismo. O marxismo na época da terceira internacional: problemas da cultura e da ideologia. Rio de Janeiro: Paz e Terra. Tradução de Carlos Nelson Coutinho, Luiz Sergio N. Henrique, Amélia Rosa Coutinho.

JAMESON, Frederic, (1997). Pós-modernismo: a lógica cultural do capitalismo tardio. $2^{\mathrm{a}}$ ed. São Paulo: Ática. Tradução de Maria Elisa Cavasco. 
A crise dos paradigmas e o marxismo entre os pesquisadores...

KONDER, Leandro, (1992). O futuro da filosofia da práxis: o pensamento de Marx no século XXI. Rio de Janeiro: Paz e Terra. , (1984). O marxismo na batalha das idéias. Rio de Janeiro: Nova Fronteira.

KUHN, Thomas, (1975). A estrutura das revoluções científicas. $5^{\mathrm{a}}$ ed. São Paulo: Perspectiva. Tradução de Beatriz V. Boeira e Nelson Boeira.

LEHER, Roberto, (1998). Da ideologia do desenvolvimento à ideologia da globalização: a educação como estratégia do Banco Mundial para o alívio da pobreza. Tese de doutorado. Faculdade de Educação da Universidade de São Paulo.

LOPES, Maria I. de S., (1997). A resistência no regime militar: o docente cientista frente à política de ciência e tecnologia. Tese de doutorado. Faculdade de Educação da Universidade Estadual de Campinas.

LÖWY, Michael, (2000). As aventuras de Karl Marx contra o Barão de Münchhausen: marxismo e positivismo na sociologia do conhecimento. $7^{\mathrm{a}}$ ed. São Paulo: Cortez. Tradução de Juarez Guimarães e Suzane Felice Léwy. , (1978). Método dialético e teoria política. $3^{\mathrm{a}}$ ed. Rio de Janeiro: Paz e Terra. Tradução de Reginaldo Di Piero.

LYOTARD, Jean-François, (1989). A condição pós-moderna. Lisboa: Gradiva.

MARX, Karl, (1983). Contribuição à crítica da economia políti$c a .2^{\mathrm{a}}$ ed. São Paulo: Martins Fontes. Tradução de Maria Helena Barreiro Alves.

, (s.d.). Critica del Programa de Gotha. In: MARX, K., ENGELS, F. Obras escogidas. Moscú: Editorial Progreso.

MARX, K., ENGELS, F., (1993). A ideologia alemã. São Paulo: Hucitec. Tradução de José Carlos Bruini e Marco Aurélio Nogueira.

MCLAREN, Peter, (1993). Pós-modernismo, pós-colonialismo e pedagogia. In: SILVA, Tomaz Tadeu da (org.). Teoria educacional crítica em tempos pós-modernos. Porto Alegre: Artes Médicas.

MORAES, Raquel de A., (1996). A política de informática na educação brasileira. Tese de doutorado. Faculdade de Educação da Universidade Estadual de Campinas.
NOSELLA, Paolo, (1998). Qual compromisso político? Ensaios sobre a educação brasileira pós-ditadura. Bragança Paulista: EDUSF , (1995). Trabalho e educação: do tripalium da escravatura ao labor da burguesia; do labor da burguesia à poesia socialista. In: GOMES, C. Minayo. Trabalho e conhecimento. São Paulo: Cortez.

PALANGANA, Isilda C., (1997). Individualidade: afirmação $e$ negação na sociedade capitalista. Tese de doutorado. Faculdade de Educação da Pontifícia Universidade Católica de São Paulo.

PEIXOTO, Madalena Guasco, (1997). Pós-modernidade, democracia e educação. Tese de doutorado. Faculdade de Educação da Pontifícia Universidade Católica de São Paulo.

PEREIRA, Wally. F. C., (1994). Educação na empresa: uma reflexão à luz das categorias habermasianas. Tese de doutorado. Faculdade de Educação da Universidade Federal do Rio de Janeiro.

SARETTA, Vilmar, (1998). Aspectos educativos na empresa e na escola. Tese de doutorado. Faculdade de Educação da Universidade de São Paulo.

SILVA, Tomaz Tadeu da, (org.) (1993). Teoria educacional crítica em tempos pós-modernos. Porto Alegre: Artes Médicas.

SOBREIRA, Henrique G., (1995). O trabalho como princípio educativo na formação do professor. Tese de doutorado. Faculdade de Educação da Universidade Federal do Rio de Janeiro.

TREIN, Eunice S., (1994). Cidadania e educação: entre o projeto e a realidade concreta. Tese de doutorado. Faculdade de Educação da Universidade Federal do Rio de Janeiro.

VATTIMO, Gianni, (1996). O fim da modernidade: niilismo e hermenêutica na cultura pós-moderna. São Paulo: Martins Fontes. Tradução de Eduardo Brandão.

Recebido em junho de 2002 Aprovado em outubro de 2002 
Ana Canen e Angela M. A. de Oliveira Multiculturalismo e currículo em ação: um estudo de caso

O multiculturalismo, campo teórico e político voltado para a valorização da pluralidade cultural e para o desafio à construção das diferenças, tem adquirido visibilidade crescente no campo educacional. Tendo em vista a incrementar a produção do conhecimento sobre possíveis formas de tradução do projeto multicultural para o currículo em ação, o presente estudo objetivou responder à seguinte questão central: o que seria uma prática pedagógica multicultural crítica? Para tal, analisa criticamente dados provenientes de um estudo de caso de cunho etnográfico, focalizando uma prática pedagógica identificada como portadora de "potenciais multiculturais". Sugere, a partir da confluência entre teoria e empiria, categorias centrais para o currículo em ação multiculturalmente comprometido.

Palavras-chave: multiculturalismo, currículo em ação, pluralidade cultural.

Multiculturalism and curriculum in action: a case study

Multiculturalism, a theoretical and political field aimed at valuing cultural diversity and challenging the construction of differences, has been gaining increasing visibility within the educational arena. Based on that approach, the present paper aims to contribute to the production of knowledge related to possible ways of translating the multicultural project into the curriculum in action. It seeks to answer the following central question: what is a critical multicultural pedagogical practice? In order to do so, it analyses data from an ethnographic case study that focused on a pedagogical practice informed by "multicultural potentials". From the articulation between theory and empirical evidence, the paper advances in the presentation of categories deemed crucial for a multiculturally oriented curriculum in action.

Key-words: multiculturalism, curriculum in action, cultural plurality.

Maria Onete Lopes Ferreira

A crise dos paradigmas e o marxismo entre os pesquisadores em trabalho $\mathrm{e}$ educação em universidades brasileiras

Tomando como problema a crise na qual mergulharam as teorias do conhecimento na atualidade, reflete sobre as conseqüências de tal momento de fragilidade teórica no campo da pesquisa educacional, especialmente entre os estudiosos que tratam de objetos referentes à relação "Trabalho e Educação". As fontes eleitas foram as teses produzidas nos Programas de Pós-Graduação em Educação das universidades PUC/SP, USP, UNICAMP, UFRJ e UFRGS, entre os anos de 1994 e 1998. O critério definidor do intervalo está amparado no fato de que, seguramente, a partir daquele momento inicial seria possível contemplar a problemática da crise dos referenciais, e que este intervalo deveria fechar-se no instante em que tivesse início o trabalho de campo. A questão norteadora da investigação teve como eixo o nível de compromisso dos pesquisadores com as teorias historicistas, em especial o marxismo, assim como com aquelas ditas pós-modernas. O resultado do trabalho demonstra ampla predominância do referencial marxista entre os pesquisadores investigados.

Palavras-chave: crise dos referenciais, marxismo, pós-moderno.

The crisis of paradigms and Marxism amongst educators Examines the consequences for educational research of the crisis in which the theories of knowledge are actually immersed. It especially examines research whose authors take as object of investigation themes concerning the relationship between work and education, since these themes are common objects of research in Post-graduate Programmes in Education in Brazil. Theses produced at PUC/SP, USP, UNICAMP, UFRJ and UFRGS, between 1994 and 1998, were examined. The period of research was determined by the year in which the crisis in social science investigation was first detected in Brazil, and the year in which this study was initiated. The aim of the investigation was to examine the nature of the research commitment to historical theories, especially Marxism, as well as to the so-called post-modern theories. The result of the investigation shows an ample predominance of Marxist theoretical frameworks among the researchers studied.

Key-words: crisis of theoretical frameworks, marxism, post-modern.

Solange Jobim e Souza e Nilton Gamba Jr.

\section{A escolarização como um projeto de} civilização

$\mathrm{O}$ artigo discute as contribuições de Michel Foucault e Norbert Elias para a historiografia da educação e para a história da escolarização. Especificamente, desenvolve, a partir de Norbert Elias, uma reflexão sobre o significado da monopolização do ensino elementar pelo Estado, no século XIX e nas sociedades ocidentais, enquanto estratégia fundamental para completar o projeto de civilização.

Palavras-chave: escolarização, civilização, Estado.

Schooling as a project of civilisation This paper focuses on the ideas of Michel Foucault and Norbert Elias and their ascendancy in the studies of the history of education and schooling. Based on Elias's studies, it has the purpose of analysing the relationship 